\title{
Commentary
}

\section{Food for thought: obstacles to menu labelling in restaurants and cafeterias}

\author{
Erica Thomas* \\ Health and Wellbeing, University of Wolverhampton, City Campus, Nursery Street, Wolverhampton WVI IAD, UK
}

Submitted 24 October 2014: Final revision received 18 June 2015: Accepted 25 June 2015: First published online 3 August 2015

\begin{abstract}
Menu labelling is recommended as a policy intervention to reduce obesity and diet-related disease. The present commentary considers the many challenges the restaurant industry faces in providing nutrition information on its menus. Barriers include lack of nutrition expertise, time, cost, availability of nutrition information for exotic ingredients, ability to provide accurate nutrition information, libel risk, customer dissatisfaction, limited space on the menu, menu variations, loss of flexibility in changing the menu, staff training and resistance of employees to change current practice. Health promotion specialists and academics involved in fieldwork must help restaurateurs find solutions to these barriers for menu labelling interventions to be widely implemented and successful. Practical support for small independent restaurants such as free or subsidised nutrition analysis, nutrition training for staff and menu design may also be necessary to encourage voluntary participation.
\end{abstract}

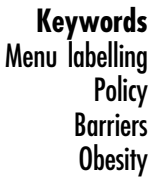

The economic impact of overweight and obesity is substantial. According to Withrow and Alter ${ }^{(10)}$, globally, overweight and obesity accounts for $9.1 \%$ of a country's total health-care expenditure, with obese individuals costing the health-care system 30\% more than their normal-weight peers. In 2007, the cost to the National Health Service attributable to overweight, obesity and related morbidity in England was $£ 4.2$ billion, the estimate of the indirect costs (i.e. costs arising from the impact of obesity on the wider economy such as loss of productivity) was $£ 2.6$ billion $^{(11)}$. In 2008 , medical costs of obesity in the USA were estimated at \$US 147 billion $^{(12)}$. Although many factors contribute to obesity, menu labelling may help to reduce consumers' energy intake which would alleviate the prevalence of obesity and co-morbidities. This in turn has economic benefits for society through decreased medical expenditure and increased productivity ${ }^{(13)}$.

Nutrition labelling has long been mandatory in the food manufacturing and food processing industries ${ }^{(14)}$. More recently, menu labelling legislation has been adopted in the USA. In 2010 Congress passed a national law requiring restaurants with twenty or more outlets to post calorie information on their menus. New regulations released by the Food and Drug Administration also require calorie labelling for prepared foods in movie theatres and vending 
machines ${ }^{(15,16)}$. In the UK, the government has launched a voluntary scheme to encourage businesses to provide calorie information for foods and non-alcoholic drinks in out-of-home settings. Despite this critics have argued that current policy does not go far enough. For example, a group of twenty-one chain restaurants in the USA sent a letter to Members of Congress urging policy makers to broaden the scope of menu labelling legislation to chains with three or more locations. They argued that current labelling legislation unfairly exempts smaller chains from its scope and excludes three times more restaurants than it includes $^{(17)}$. Although the total number of independent restaurants in the USA outnumbers chain restaurants in terms of unit count ${ }^{(18)}$, it is not the actual number of restaurants that impacts exposure to menu labelling but the market share. According to the NPD Group, major chains account for $64 \%$ of all restaurant traffic compared with $25 \%$ for small independent restaurants ${ }^{(18)}$. In the UK, Glayzer and Mitchell ${ }^{(19)}$ report that the voluntary scheme is unlikely to be implemented by restaurants selling foods high in calories. In fact, many restaurant operators concede that they would not label their menus unless it was required by law ${ }^{(20)}$. Thus in the UK critics have suggested that a mandatory menu labelling scheme would be more effective ${ }^{(19)}$

\section{Discussion}

In contrast to the food manufacturing industry, the restaurant industry faces some unique operational challenges that may require attention if menu labelling is to be implemented widely and successfully. First, chefs are taught to cook by touch, taste and proportion rather than following standardised instructions. Subsequently restaurants where chefs do not follow a standardised recipe run the risk of unintentionally providing inaccurate information to consumers ${ }^{(2)}$. For these chefs then, creating and adhering to standardised recipes would require more administrative time and greater accuracy in cooking processes. Some have argued that this would hamper chef creativity and kill innovation ${ }^{(21)}$. Furthermore, all staff responsible for preparing and presenting food would need to be thoroughly trained in the importance of adhering to the recipes. These concerns do not apply to the majority of restaurants and fast-food outlets targeted by the menu labelling law in the USA, as many chains already follow standardised recipes and cooking procedures. It may, however, affect the willingness of small independent operators to label their menus voluntarily ${ }^{(22)}$.

The accuracy of nutrition information is also dependent on the accuracy of the nutrition analysis. There are two methods to analyse the nutrient content of menu items: database and laboratory analysis. Laboratory analysis generally involves high cost in terms of time and money ${ }^{(23)}$; thus for most restaurant companies, the database method is the quickest and most cost-effective means of obtaining nutrition information. Many restaurant meals contain numerous ingredients and involve complex cooking processes, so it is important to have a qualified nutrition professional perform the computerised analysis. For this reason many chain restaurants employ a registered dietitian who calculates the nutrition information for them. Even then database analysis may not be reliable since nutrient levels are affected by many factors including processing, storage and geographic region where a fruit or vegetable is grown ${ }^{(24)}$. The availability of nutrition information for certain foods or exotic cooking ingredients may also affect the accuracy of database analysis. Moreover, it would be difficult to provide accurate measures in a buffet-style restaurant ${ }^{(25)}$ and impractical and onerous for 'variable' menu items such as pizza toppings that could have calorie ranges. Given that estimates of nutritional information in restaurants are prone to error, it is not surprising that owners have expressed concerns about libel risks ${ }^{(26)}$. In summary, an accurate nutrition analysis requires a detailed and accurate recipe, a qualified nutrition professional with expertise in nutrition analysis and a high-quality database and/or laboratory analysis. The difficulties of standardisation and the cost of providing precise nutritional information suggest that it may be difficult for small independent restaurants to achieve and may put them at risk of closure ${ }^{(25)}$. As such, broadening the scope of menu labelling legislation to chains with three or more locations, as some critics suggest, may not be politically viable ${ }^{(17)}$. Conversely, some chain restaurants already provide nutrition information on their website, e.g. MacDonald's. In this instance any additional costs would arise from adjusting the menus and menu boards as opposed the nutrition analysis per se.

There are concerns among restaurant operators that providing nutrition information may affect ordering behaviour and have a detrimental effect on revenue ${ }^{(26)}$. For example, there are fears that menu labelling might lead to reduced demand for profitable items or encourage consumers to switch the source of their meals from one food-service outlet to another. Despite concerns over revenue, there is growing evidence that menu labelling does not affect sales ${ }^{(27)}$. The British Hospitality Association argues that menu labelling is largely ineffective and could result in huge cost to the industry with little benefit to public health $^{(28)}$. This is backed up by several field studies that show menu labelling has little effect on energy intake and/or eating behaviour ${ }^{(27,29-32)}$. Krieger and Saelens ${ }^{(33)}$ argue that when assessed among all consumers, not just those who see and use the labels, the impact of menu labelling is only ten to twenty calories (10-20 kcal, $42-84 \mathrm{~kJ}$ ) per meal. Thus although menu labelling has received a high degree of support from public health, evidence concerning its impact is mixed. Gittelsohn et $a l .{ }^{(34)}$ also cast doubt on the generalisability of findings from existing research, stating that many studies are 
poorly designed and lack a control group and random assignment to conditions.

The menu is one of the most important components in a restaurant. It is a major communication device that projects the personality and concept of the restaurant and an advertisement tool ${ }^{(35)}$. Besides pricing, descriptive and evocative names for foods are frequently found on restaurant menus ${ }^{(36)}$ and, in more expensive restaurants, the ingredients and method of cooking are often provided in an attempt to impress the consumer. Operators then are confronted with the challenge of finding space for nutrition information on menus that are already overcrowded. This is complicated even further when there are menu variations. For example, restaurants and cafés typically sell hot drinks in a range of different sizes with various types of milk. From an operational perspective listing nutrition information for all options on the menu may be impractical due to lack of space. Adjusting menus and menu boards to provide information for all possible choices may also be time-consuming and expensive. Adding additional information might also mean that operators have to downplay or remove some other valuable piece of information about their product ${ }^{(13)}$. For the consumer, listing information for all options on the menu may lead to information overload ${ }^{(37)}$. Furthermore, given that consumers want menus that are aesthetically pleasing ${ }^{(38)}$, improper menu presentation may lead to customer dissatisfaction, decreased profit and the ultimate failure of a restaurant operation ${ }^{(35)}$.

Long-term implementation of menu labelling entails additional cost and planning, especially when menus are updated regularly. As such, some restaurant operators worry that providing nutrition information may limit flexibility in changing the menu, resulting in longer implementation times. Limited flexibility and long implementation times for menus may mean that consumers find food choices restrictive. Operators are also concerned that it may be too difficult and time-consuming to provide information about foods and drinks that are one-offs given the extra time required to calculate or obtain nutritional values $^{(37)}$. Under new Food and Drug Administration ${ }^{(11)}$ regulations calorie information is not required for specials or 'one-off' items; however, Guilding ${ }^{(39)}$ argues that the unpredictable nature of the hospitality industry means that food preparation methods and menus are continually adjusted. For example, to make sure that restaurants operate in a cost-effective fashion they change their menus on a regular basis to ensure efficient use of highly perishable foods.

Regular nutrition training for waiting staff may be necessary so that they can guide customers on menu choices, answer customer questions or respond to unusual requests ${ }^{(40)}$. Nothwehr et al. ${ }^{(41)}$ report that customers ask more questions about food content and preparation methods when signs promoting healthier options are available. Given high staff turnover in the catering industry, it is likely that training will need to be repeated regularly ${ }^{(40)}$. In addition to staff training, communication between different members of staff is also vital for the success of menu labelling. Zick et al. ${ }^{(40)}$ report that the creation of six weekly menus, labelled for calories, saturated and polyunsaturated fat, fibre and sodium, in a hotel restaurant took two weeks and depended on the cooperation of the head chef, restaurant manager, operations manager and the nutritionist. As such, chefs will need to become more familiar conversing with nutritionists and ensure that the administration team is updated on a regular basis so that team members have the correct information to present on the menu. Another worry for restaurant operators is how the impact of regularly updating the constant stream of product and recipe data will affect their already stretched catering team, as there is likely to be some resistance by employees to change their current practice. For example, a recent survey found that $64 \%$ of independent restaurant operators felt that they were too busy to provide nutrition information on their menus ${ }^{(20)}$. Indeed, perceived burden and perceived lack of benefits are reported as a barrier to menu labelling, as is mistrust of health educators by restaurant owners ${ }^{(34)}$.

\section{Implications for research and practice}

It is clear that small locally owned restaurants, in particular, need information and support for menu labelling to be implemented voluntarily. Indeed, research has shown that free nutrition counselling, nutritional analysis and advertising are motivating factors encouraging voluntary participation $^{(42)}$. Unlike other professions such as dietetics, chefs have no specific training in nutrition analysis. It seems likely then that nutrition education for chefs is key to longterm and successful menu labelling. Regular nutrition training for restaurant staff to enable them to advise consumers on menu choices is also necessary.

According to the Food and Drug Administration, the economic impact of complying with calorie labelling legislation in the USA is somewhere in the region of \$US $76 \cdot 8-82 \cdot 3$ million per year over 10 years; initial set-up costs are estimated at \$US 1100 per establishment ${ }^{(13)}$. Others have estimated an average cost per restaurant of \$US 3700 for menu analysis alone ${ }^{(42)}$. It is not surprising then that the restaurant industry perceives labelling policy as a potential threat to its profits, especially in these difficult economic times. It is likely that increased costs would be passed on to the consumer in the form of higher prices or reduced menu choices. More research needs to be done examining the change in restaurant net return over the direct costs of menu labelling. More research also needs to examine how consumers' 'new choices' might affect restaurant profitability to ensure that menu labelling interventions are financially feasible across the board for both owners and the consumer. 
Nutrition labelling certainly does take up more space ${ }^{(40)}$ and there are no clear and practical guidelines as to the best format for nutrition labelling on menus and menu boards. For example, it will not be possible to provide as much nutrition information on menus as on packaged products without making the menu several pages longer, nor will it be possible to use the same format ${ }^{(13)}$. To circumvent these problems Lee-Kwan et al. ${ }^{(43)}$ provided restaurants with high-quality, attractive menus displaying appealing photographs of their food. Researchers found that both owners and consumers liked the new materials, which led to higher acceptability. In another study, Brit et $a l{ }^{(42)}$ used a calories/fat/sodium/carbohydrates format (e.g. 750/9/900/30) with a descriptive key to display nutrition information and found that space was not a significant barrier. However, further research is needed to determine the most appropriate format for nutrition labels on menus and menu boards.

Some restaurant managers believe that providing nutrition information may limit flexibility in changing the menu, resulting in decreased revenue ${ }^{(22,40)}$. However Zick et al. ${ }^{(40)}$ suggest that 'healthy eating' could be used as a marketing tool and that providing nutrition information could be good for business and a way to attract customers. Indeed, menu labelling policy designed to affect consumer choice can stimulate action from the restaurant industry ${ }^{(44)}$. For example, since menu labelling legislation took effect, several establishments in the USA have reported changes to their menus. Cosi's has switched to using low-fat mayonnaise saving 350 calories ( $350 \mathrm{kcal}, 1464 \mathrm{~kJ}$ ) on some sandwiches; Starbucks has switched from whole milk to $2 \%$ fat milk as standard; and Applebee's is pushing a new low-calorie menu with choices under 550 calories $(550 \mathrm{kcal}, 2300 \mathrm{~kJ})^{(45)}$. Menu labelling can also impact individuals who may not pay attention to nutrition labels, since menu labelling creates an incentive for restaurants to reformulate and improve the nutritional profile of their menu items.

\section{Conclusion}

The restaurant industry faces several practical challenges to nutrition information provision. Despite this, the industry has a crucial part to play in facilitating healthy choices in the battle against obesity. Without expert advice, technical assistance and financial support, especially during the initial stages of implementation, small locally owned restaurants may find it difficult to accomplish this mission. Public health practitioners and academics should focus on educating and motivating restaurant owners about the benefits of menu labelling, as well as offering more practical support in terms of free or subsidised nutrition analysis, nutrition training for staff and menu design. Finally, communicating with restaurant owners, building a strong rapport and establishing trust are likely to be key to overcoming many of the barriers associated with menu labelling ${ }^{(43)}$.

\section{Acknowledgements}

Financial support: This research received no specific grant from any funding agency in the public, commercial or not-for-profit sectors. Conflict of interest: None. Authorship: E.T. is the sole author of this commentary. Ethics of buman subject participation: Not applicable.

\section{References}

1. Roberto CA, Schwartz MB \& Brownell KD (2009) Rationale and evidence for menu-labelling legislation. Am J Prev Med 37, 546-551.

2. Larson N \& Story M (2009) Menu labelling: does providing nutrition information at the point of purchase affect consumer behaviour? http://www.rwjf.org/content/dam/farm/reports/ issue_briefs/2009/rwjf42563 (accessed October 2014).

3. Pulos E \& Leng K (2010) Evaluation of a voluntary menu-labelling program in full-service restaurants. $\mathrm{Am} \mathrm{J}$ Public Health 100, 1035-1039.

4. Lachat C, Nago E, Verstraeten R et al. (2012) Eating out of home and its association with dietary intake: a systematic review of the evidence. Obes Rev 13, 329-346.

5. Young LR \& Nestle M (2003) Expanding portion sizes in the US marketplace: implications for nutrition counselling. $J \mathrm{Am}$ Diet Assoc 103, 231-234.

6. Todd JE, Mancino L \& Lin B (2010) The Impact of Food Away From Home on Adult Diet Quality, Economic Research Report no. ERR-90. Washington, DC: US Department of Agriculture, Economic Research Service.

7. Lee-Kwan S, Pan L, Maynard L et al. (2014) Restaurant menu labelling use among adults - 17 states, 2012. MMWR Morb Mortal Wkly Rep 63, 581-584.

8. Harnack LJ \& French SA (2008) Effect of point-of-purchase calorie labelling on restaurant and cafeteria food choices: a review of the literature. Int J Behav Nutr Phys Act 5, 51.

9. Bassett MT, Dumanovsky T, Huang C et al. (2008) Purchasing behaviour and calorie information at fast-food chains in New York City, 2007. Am J Public Health 98, $1457-1459$.

10. Withrow D \& Alter D (2011) The economic burden of obesity worldwide: a systematic review of the direct costs of obesity. Obes Rev 12, 131-141.

11. Butland B, Jebb S, Kopelman P et al. (2007) Tackling Obesities. Future Choices - Project Report, 2nd ed. London: Foresight Programme of the Government Office for Science; available at https://www.gov.uk/government/uploads/system/uploads/ attachment_data/file/287937/07-1184x-tackling-obesities-futurechoices-report.pdf

12. Finkelstein E, Trogdon J, Cohen J et al. (2009) Annual medical spending attributable to obesity: payer and service specific estimates. Health Aff (Millwood) 28, W822-W831.

13. Food and Drug Administration (2011) Food Labelling: Nutrition Labelling of Standard Menu Items in Restaurants and Similar Retail Food Establishments Notice of Proposed Rulemaking. http://www.fda.gov/downloads/Food/IngredientsPackaging Labeling/UCM249276.pdf (accessed April 2015).

14. US Government Publishing Office (1990) Nutrition Labelling and Education Act of 1990, Public Law 101-535. http:// www.gpo.gov/fdsys/pkg/STATUTE-104/pdf/STATUTE-104Pg2353.pdf (accessed March 2015).

15. Food and Drug Administration (2014) Final Rule: Nutrition Labeling of Standard Menu Items in Restaurants and Similar Retail Food Establishments. https://www.federalregister. gov/articles/2014/12/01/2014-27833/food-labeling-nutritionlabeling-of-standard-menu-items-in-restaurants-and-similarretail-food (accessed March 2015). 
16. Food and Drug Administration (2014) Final Rule: Calorie Labeling of Articles of Food in Vending Machines. https:// www.federalregister.gov/articles/2014/12/01/2014-27834/ food-labeling-calorie-labeling-of-articles-of-food-in-vendingmachines (accessed March 2015).

17. Frumkin P (2009) Chains urge congress to broaden labeling bill. Nation's Restaurant News, 3 August. http://nrn.com/ archive/chains-urge-congress-broaden-labeling-bill (accessed June 2015).

18. NDP Group (2015) Chains keep restaurant traffic stable while visits to independents decline in second quarter, reports NDP. https://www.npd.com/wps/portal/npd/ us/news/press-releases/chains-keep-restaurant-traffic-stablewhile-visits-to-independents-decline-in-second-quarter-reportsnpd/ (accessed June 2015).

19. Glayzer A \& Mitchell J (2008) Ignorance is Not Bliss When Eating Out: The Need for Nutrition Labelling at Fast Food and Other Chain Restaurants. London: The Food Commission.

20. Mah C, Vanderlinden L, Mamatis D et al. (2013) Ready for policy? Stakeholder attitudes toward menu labelling in Toronto, Canada. Can J Public Health 104, e229-e234.

21. Brand J (2014) Don't believe in labels? Hotel Owner, September issue. http://www.caternet.co.uk/wp-content/ uploads/2014/09/Hotel-Owner-Sep-14.pdf (accessed October 2014).

22. Almanza BA, Nelson D \& Chai S (1997) Obstacles to nutrition labelling in restaurants. J Am Diet Assoc 97, 157-161.

23. Bognar A \& Piekarski J (2000) Guidelines for recipe information and calculation of nutrient composition of prepared foods (dishes). J Food Compost Anal 13, 391-410.

24. Peregrin T (2011) Next on the menu: labelling law could mean new career opportunities for RDs. J Am Diet Assoc 111, Suppl. 1, S12-S14.

25. Alexander M, O'Gorman K \& Wood K (2010) Nutritional labelling in restaurants: whose responsibility is it anyway? Int J Contemp Hospit Manage 22, 572-579.

26. Yamamoto JA, Yamamoto JB, Yamamoto BE et al. (2005) Adolescent fast food and restaurant ordering behaviour with and without calorie and fat content menu information. J Adolesc Health 37, 397-402.

27. Ellison B, Lusk JL \& Davis D (2014) The effect of calorie labels on caloric intake and restaurant revenue: evidence from two full-service restaurants. J Agric Appl Econ 46, 173-191.

28. Paskin B (2009) Menu labelling scheme inappropriate says BHA. http://www.bighospitality.co.uk/Hot-Topics/Calorielabelling/Menu-labelling-scheme-inappropriate-says-BHA (accessed March 2015).

29. Downs JS, Wisdom J, Wansink B et al. (2013) Supplementing menu labelling with calorie recommendations to test for facilitation effects. Am J Public Health 103, 1604-1609.
30. Elbel B, Kersh R, Brescoll VL et al. (2009) Calorie labelling and food choices: a first look at the effects on low-income people in New York City. Health Aff (Millwood) 28, w1110-W1112.

31. Finkelstein EA, Strombotne KL, Chan NL et al. (2011) Mandatory menu labelling in one fast-food chain in King County, Washington. Am J Prev Med 40, 122-127.

32. Mayer JA, Brown TP, Heins JM et al. (1987) A multicomponent intervention for modifying food selections in a worksite cafeteria. J Nutr Educ 19, 277-280.

33. Krieger J \& Saelens BE (2013) Impact of Menu Labelling on Consumer Behaviour: A 2008-2012 Update. Minneapolis, MN: Healthy Eating Research; available at http://healthy eatingresearch.org/wp-content/uploads/2013/12/HER-RRMenu-Labeling-FINAL-6-2013.pdf

34. Gittelsohn J, Lee-Kwan SH \& Batorsky B (2013) Communitybased interventions in prepared-food sources: a systematic review. Prev Chronic Dis 10, 130073.

35. Din N, Zahari M, Othman C et al. (2012) Restaurant operators' receptiveness towards providing nutritional information on menu. Soc Behav Sci 50, 699-709.

36. Wansink B, Painter J \& Ittersum KV (2001) Descriptive menu label's effect on sales. Cornell Hotel Restaurant Admin $Q$ 42, issue 6, 68-72.

37. Department of Health (2011) Guidance on voluntary calorie labelling for caterers (2011). https://responsibilitydeal.dh. gov.uk/wp-content/uploads/2013/04/Illustrative-guidanceon-voluntary-calorie-labelling-for-caterers-2011.pdf (accessed October 2014).

38. Drydale JA \& Galipue JA (2008) Profitable Menu Planning, 4 th ed. New Jersey: Pearson.

39. Guilding C (2006) Financial Management for Hospitality Decision Makers. Oxford: Butterworth-Heinemann.

40. Zick A, Wake Y \& Reeves S (2010) Nutrition labelling in restaurants; a UK-based case study. Nutr Food Sci 40, 557-565.

41. Nothwehr F, Snetselaar L, Dawson J et al. (2013) Promoting healthy choices in non-chain restaurants: effects of a simple cue to customers. Health Promot Pract 14, 132-138.

42. Brit JW, Frandsen K, Leng K et al. (2011) Feasibility of voluntary menu labelling among locally owned restaurants. Health Promot Pract 12, 18-24.

43. Lee-Kwan SH, Goedkoop S, Young R et al. (2013) Development and implementation of the Baltimore healthy carry-outs feasibility trial: process evaluation results. $B M C$ Public Health 13, 638.

44. Hawkes C, Smith T, Jewell J et al. (2015) Smart food policies for obesity prevention. Lancet 385, 2410-2421.

45. Dumanovsky T, Huang C, Nonas C et al. (2011) Changes in energy content of lunchtime purchases from fast food restaurants after introduction of calorie labelling: cross sectional customer surveys. BMJ 343, d 4464. 